\title{
Influence of C-rates on Consistency among Batteries in a Set in a Low-temperature Environment
}

\author{
Hongwei Wang ${ }^{1, *}$, Qiang $\mathrm{Ma}^{1}$, Zhengjian $\mathrm{Gu}^{2}$, Yusong $\mathrm{Zhu}^{3}$, Bin $\mathrm{Hu}^{4}$, Yanling $\mathrm{Fu}^{1}$ and Ziqiang Tao ${ }^{1}$ \\ ${ }^{1}$ Institute of Industrial and Consumer Product Safety, Chinese Academy of Inspection and Quarantine, No. 11, Ronghua South Road, \\ Yizhuang, Daxing, Beijing, 100176, China \\ ${ }^{2}$ Wuxi Institution of Supervision and Inspection on Product Quality, Wuxi, 214028, China \\ ${ }^{3}$ Nanjing Tech University, Nanjing, Jiangsu Province, 211816, China \\ ${ }^{4}$ China Special Equipment Inspection and Research Institute, 100029, China
}

\begin{abstract}
The methods of examining and evaluating the consistency among batteries in a set are mostly meant for the batteries in a conventional application environment. Therefore, this article has studied the influence of C-rates on the consistency among batteries in a set in a low-temperature environment, as well as the regular pattern of changes in charging and discharging currents, providing reference data for the correct use of batteries in a low-temperature environment, and establishing a research base for the improvement on the performance of batteries.
\end{abstract}

\section{Introduction}

The consistency of Lithium-ion batteries refers to the uniformity in initial performance indexes across all individual component batteries, including capacity, impedance, electrode's electrical characteristics, electric connection, thermal characteristics, and decay rate. The inconsistency in the factors above will directly affect the difference in output electric parameters during operation. The initial inconsistency will gradually change as the cycle of recharge and discharge continues during the use of batteries, leading to a bigger difference in the status of individual batteries (SOC, voltage, etc.)[1-5]. The working conditions inside a set of batteries are not all the same for individual batteries, and this results in so increasingly higher a degree of inconsistency among individual batteries in use, that the performance of some individual batteries is impaired in an accelerated manner under certain circumstances, and the batteries set finally become ineffective too early.
Therefore, this article has studied the influence of Crates on the consistency among batteries in a set in a low-temperature environment, providing reference data for the correct use of batteries.

\section{Test}

For the purpose of this article, at $-10^{\circ} \mathrm{C},-20^{\circ} \mathrm{C}$, and $30^{\circ} \mathrm{C}, 4$ batteries that maintain good consistency in capacity $(12 \mathrm{Ah})$ and internal resistance $(\leq 6 \mathrm{~m} \Omega)$ but are inconsistent in initial open circuit potential are chosen separately, to form two battery packs respectively in series connection, and recharge and discharge at $0.2 \mathrm{C}, 1 / 3 \mathrm{C}, 1.5 \mathrm{C}$, and $2 \mathrm{C}$, while voltage and temperature measurements are made in real time.

\section{Results}

The test results are as shown in Table 1, and the realtime voltages during the test are as shown in Figures 1 to 3 .

Table 1. Test results

\begin{tabular}{|c|c|c|c|c|}
\hline \multicolumn{2}{|c|}{ Conditions for the test } & Serial number of specimen & Highest charging voltage/ V & Lowest discharging voltage/ V \\
\hline \multirow{3}{*}{$-10^{\circ} \mathrm{C}$} & $0.2 \mathrm{C}$ & $0.2 \mathrm{C}-20+25$ & 8.4004 & 5.4 \\
\cline { 2 - 5 } & $1 / 3 \mathrm{C}$ & $1 / 3 \mathrm{C}-2+10$ & 8.4002 & 5.4 \\
\cline { 2 - 5 } & $1.5 \mathrm{C}$ & $1.5 \mathrm{C}-7+9$ & 8.967 & 5.4 \\
\cline { 2 - 5 } & $2 \mathrm{C}$ & $2 \mathrm{C}-45+46$ & 8.4916 & 5.4 \\
\hline
\end{tabular}




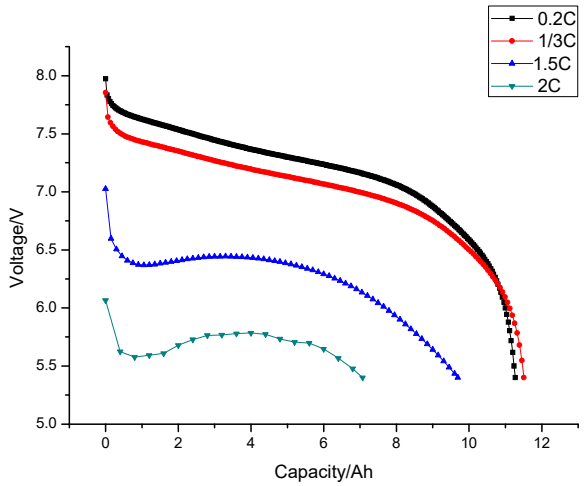

Fig. 1. The discharge curve of a set of Lithium-ion batteries at different C-rates at $-10^{\circ} \mathrm{C}$

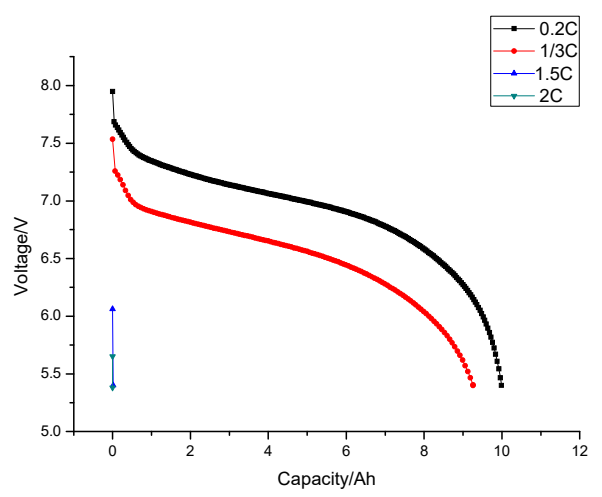

Fig. 2. The discharge curve of a set of Lithium-ion batteries at different $\mathrm{C}$-rates at $-20^{\circ} \mathrm{C}$

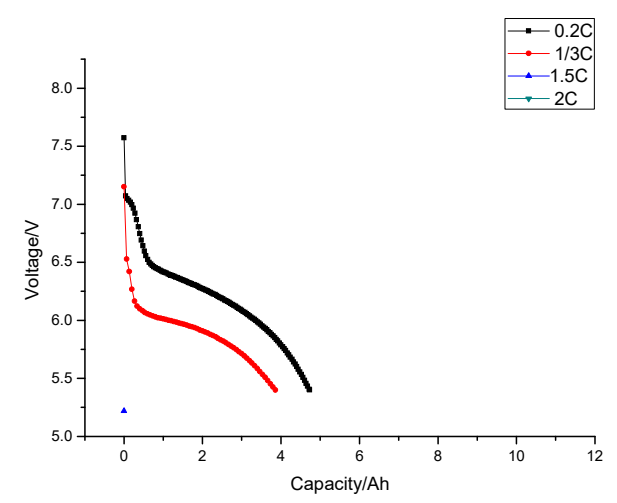

Fig. 3. The discharge curve of a set of Lithium-ion batteries at different $\mathrm{C}$-rates at $-30^{\circ} \mathrm{C}$

It can be learnt from the Figures 1 to 3 that, with the decrease in temperature, the highest discharging current that can be generated by the batteries set has decreased gradually. At $-10^{\circ} \mathrm{C}$, the batteries set can discharge at a constant current of $2 \mathrm{C}(24 \mathrm{~A})$. At $-20^{\circ} \mathrm{C}$, the batteries set can discharge at a constant current of $1 / 3 \mathrm{C}(4 \mathrm{~A})$. At $-30^{\circ} \mathrm{C}$, the batteries set can discharge at a constant current of $1 / 3 \mathrm{C}(4 \mathrm{~A})$.
In the case of discharge at a higher current and at a low temperature, the discharge curve takes on a non-linear form, with apparent peaks and troughs, and large fluctuation in discharging voltage. Take the discharge at a constant current of $1.5 \mathrm{C}$ (18A) for example, at $20^{\circ} \mathrm{C}$, the discharge curve is relatively normal, without peaks or troughs, but when the ambient temperature has decreased to $-10^{\circ} \mathrm{C}$, the discharge curve obviously shows troughs. This indicates that, when a battery is discharged at a high current and at a low temperature, because of the low temperature of the battery at the beginning, the active substances in the battery cannot be fully utilized, and the electrode is seriously polarized, while the internal resistance of the battery is high. As a result of this, at the initial stage of discharge, the discharging voltage of the battery drops fast. As the process of discharge goes on, because of the high internal resistance of the battery, a great amount of heat is generated inside the battery, causing the temperature of the battery to rise rapidly, so as to enable the active substances part of the battery to be activated, thus causing the discharge voltage of the battery to begin rising. As the temperature of the battery goes up, the internal resistance of the battery starts to decrease, producing less heat. Since the ambient temperature is invariably maintained at $-10^{\circ} \mathrm{C}$, the temperature of the battery begins to drop, and the discharging voltage of the battery also decreases accordingly.

When the ambient temperature drops to $-30^{\circ} \mathrm{C}$, the voltage decreases from $8.30 \mathrm{~V}$ to $5.22 \mathrm{~V}$ in a very short period of time (about 1 second), and afterwards rises from $5.22 \mathrm{~V}$ to $7.60 \mathrm{~V}$ in a very short period of time (about 1 second). And normal discharge is already impossible.

The charging curves of a set of batteries at different temperatures and at different $\mathrm{C}$-rates are as shown in Figures 4 to 6.

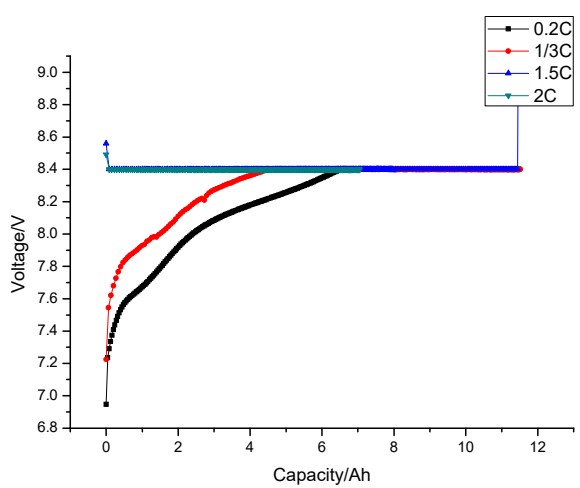

Fig.4. The charging curve of the Lithium-ion batteries set at different $\mathrm{C}$-rates at $-10^{\circ} \mathrm{C}$ 


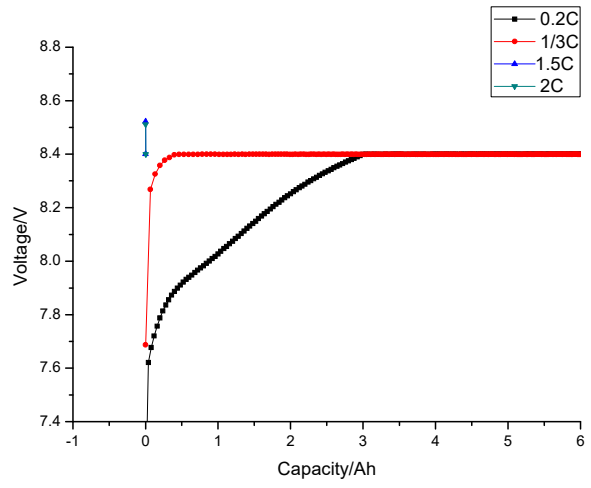

Fig.5. The charging curve of the Lithium-ion batteries set at different $\mathrm{C}$-rates at $-20^{\circ} \mathrm{C}$

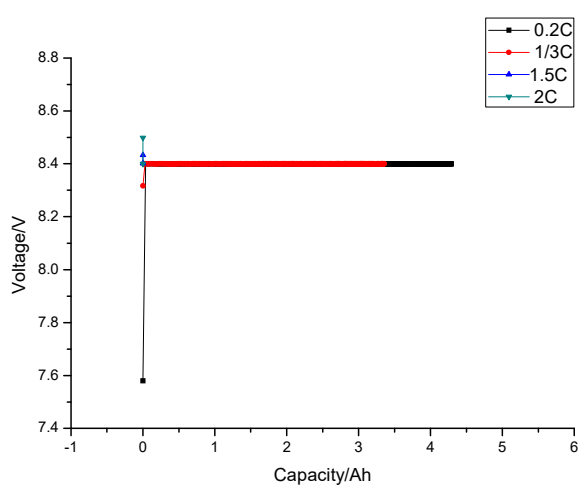

Fig.6. The charging curve of the Lithium-ion batteries set at different $\mathrm{C}$-rates at $-30^{\circ} \mathrm{C}$

It can be seen from the charging curve at different temperatures that, as compared with the characteristics of the battery discharge at a low temperature, the performance of the battery on charging decays more obviously. At $-10^{\circ} \mathrm{C}$, the battery already cannot be charged at $1.5 \mathrm{C}$ or $2 \mathrm{C}$. At $30^{\circ} \mathrm{C}$, the charging of the battery becomes abnormal, without the process of charging at a constant current at all, and the instant that charging current is switched on, the voltage on the batteries set end rises rapidly to a cut off voltage of $8.4 \mathrm{~V}$, immediately followed by a constant-voltage charging stage.

Figures 7 and 8 show the changes in the voltage of the Lithium-ion batteries set that has come to a halt after the process of charging and discharging at different $\mathrm{C}$-rates at $-10^{\circ} \mathrm{C}$.

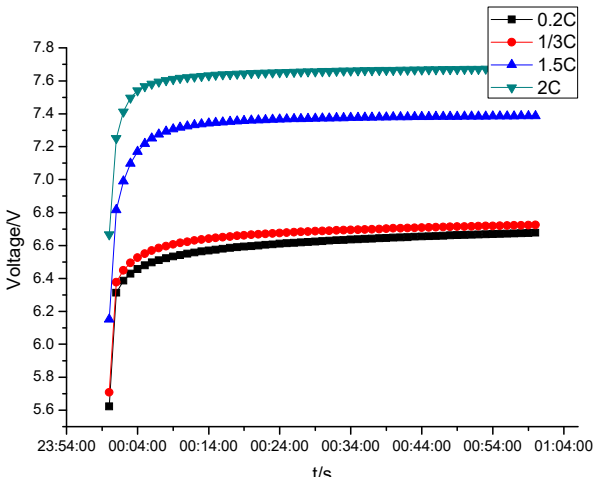

Fig. 7. The changes in the voltage of the Lithium-ion batteries set that has come to a halt after discharge at different C-rates at $-10^{\circ} \mathrm{C}$.

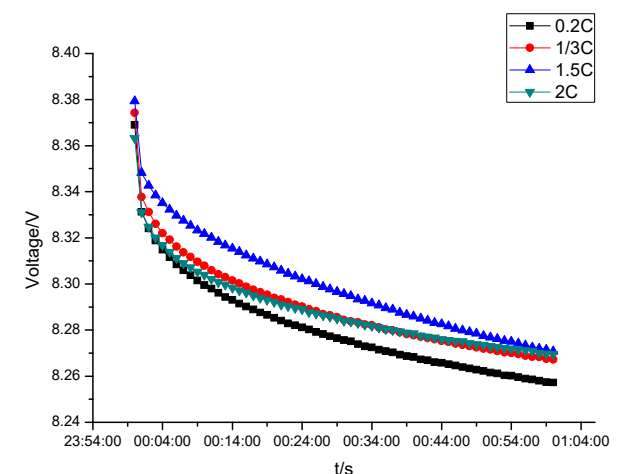

Fig. 8. The changes in the voltage of the Lithium-ion batteries set that has come to a halt after recharge at different $\mathrm{C}$-rates at $-10^{\circ} \mathrm{C}$

As seen in Figures 7 and 8 , at $-10^{\circ} \mathrm{C}$, when the batteries set comes to a halt after the discharge at different $\mathrm{C}$-rates, the voltages go up again in varying degrees, where, the voltages at $2 \mathrm{C}$ and $1.5 \mathrm{C}$ rise up the fast, to a higher extent of voltage rise. Voltages have also fallen back in varying degrees when it comes to a halt after the discharge at different $\mathrm{C}$-rates.

\section{Conclusion}

1) With the decrease in temperature, the highest current at which the batteries set can be discharged decreases gradually. At $-10^{\circ} \mathrm{C}$, the batteries set can be discharged at a constant current of $2 \mathrm{C}(24 \mathrm{~A})$. At $20^{\circ} \mathrm{C}$, the batteries set can be discharged at a constant current of $1 / 3 \mathrm{C}(4 \mathrm{~A})$.

In the case of discharge at a higher current and at a low temperature, the discharge curve takes on a non-linear form, with apparent peaks and troughs, and large fluctuation in discharging voltage. At $20^{\circ} \mathrm{C}$, the discharge curve is relatively normal, without peaks or troughs, but when the ambient temperature has decreased to $-10^{\circ} \mathrm{C}$, the discharge curve obviously 
shows troughs. This is mainly because that, the temperature of the battery is low at the beginning of the charging and discharging process at a low temperature, and the active substances in the battery cannot be fully utilized, and the electrode is seriously polarized, while the internal resistance of the battery is high, and as a result of this, at the initial stage of discharge, the discharging voltage of the battery drops fast, and as the process of discharge goes on, because of the high internal resistance of the battery, a great amount of heat is generated inside the battery, causing the temperature of the battery to rise rapidly, so as to enable the active substances part of the battery to be activated, thus causing the discharge voltage of the battery to begin rising, and as the temperature of the battery goes up, the internal resistance of the battery starts to decrease, producing less heat, and since the ambient temperature is invariably maintained at $-10^{\circ} \mathrm{C}$, the temperature of the battery begins to drop, and the discharging voltage of the battery also decreases accordingly. When the ambient temperature reaches $-30^{\circ} \mathrm{C}$, normal discharge is already impossible.

2) It can be seen from the charging curve at different temperatures that, as compared with the characteristics of the battery discharge at a low temperature, the performance of the battery on charging decays more obviously. At $-10^{\circ} \mathrm{C}$, the battery already cannot be charged at $1.5 \mathrm{C}$ or $2 \mathrm{C}$. At $30^{\circ} \mathrm{C}$, the charging of the battery becomes abnormal, without the process of charging at a constant current at all, and the instant that charging current is switched on, the voltage on the batteries set end rises rapidly to a cut off voltage of $8.4 \mathrm{~V}$, and a constant-voltage charging stage ensues immediately.

\section{Acknowledgements}

The authors would like to acknowledge the financial support provided for this research work by Fund: National key $R$ \& $D$ program of China (2017YFF0210703), (2017YFF0210002) and (2018YFF021550103).

\section{References}

1. LIU Shiqiang, BU Xiangjun, BAI Guangli. et al. Study on Cycle Life of LFP High Power Traction Battery Under Different Charge Rate A reference [J]. Journal of Chongqing University of Technology( Natural Science), 2018. 32(6): 8-13

2. SOMERVILLE L, BARENO J, TRASK S, et al. The effect of charging rate on the graphite electrode of commercial lithiumion cells: A postmortem study [J]. Journal of Pow-er Sources,
2016, 335: 189-196

3. FAN Hao-tian, XIE Huan, ZHU Shun-liang. Experimental Study on Cycle Performance of Composite Material Lithium-Ion Batteries with Different Charging Rates [J]. Electromechanical Engineering Technology. 2019: 192-194

4. Aurbach D, Markovsky B, Rodkin A, et al. An analysis of rechargeable lithium-ion batteries after prolonged cycling $[\mathrm{J}]$. Electrochimica Acta, 2002, 47(12): 1899-1911.

5. WANG Fang, SUN Zhipeng, LIN Chunjing, et al.Experi-mental Analysis of Internal Resistance of Energy Type $\mathrm{LiFePO}_{4}$ Power Batteries and Its Influencing Factors $[\mathrm{J}]$. Journal of Chongqing University of Technology ( Natural Science), 2017( 8) : 44- 50 